\title{
The Trend of Labor Analgesia in the World and China: A Bibliometric Analysis of Publications in Recent 30 Years
}

This article was published in the following Dove Press journal: Journal of Pain Research

\author{
Huan Zheng ${ }^{1-3, *}$ \\ Bi-Xin Zheng ${ }^{1,2,4, *}$ \\ Xue-Mei Lin ${ }^{1,2}$
}

'Key Laboratory of Birth Defects and Related Diseases of Women and Children (Sichuan University), Ministry of Education, Chengdu 6I004I, People's Republic of China; ${ }^{2}$ Department of Anesthesiology, West China Second University Hospital, Sichuan University, Chengdu 61004I, People's Republic of China; ${ }^{3}$ Department of Anesthesiology, Sichuan Academy of Medical Sciences \& Sichuan Provincial People's Hospital, Chengdu 610072, People's Republic of China; ${ }^{4}$ Department of Pain Management, West China Hospital, Sichuan University, Chengdu 61004I, People's Republic of China

*These authors contributed equally to this work

Correspondence: Xue-Mei Lin Email xuemeilin_scu@163.com
Purpose: Labor analgesia is part of the most important tasks an anesthesiologist needs to deal with. With the "two-child policy" in China, the number of parturients has increased significantly, labor analgesia more should be valued. There has been a tremendous change on labor analgesia research in China and around the world; however, broader trends in the prevalence and scope of labor analgesia research remain underexplored. The current study quantitatively analyzes trends in labor analgesia research publications in the past 30 years.

Methods: A bibliometric approach was used to search Scopus, PubMed, Web of Science and the China National Knowledge Infrastructure for all labor analgesia-related research articles. The research progress and growing trend were quantitatively analyzed by total publications, research types, research institutions, journal impact factors, and author's contribution. Total citations frequency, average citations per item and h-index were used for evaluating literature quantity. Results: From 1988 to 2018, over 8000 documents in labor analgesia research field were published worldwide. According to Scopus, 68.2\% papers of all documents were articles. The USA published the largest number of articles $(2204,27.45 \%)$. China had published 175 articles $(2.18 \%)$, ranking the 11 th. According to WOS, there were 221 research categories for labor analgesia articles all over the world. The total citations were 76,207, average 9.086 citations per item, and the h-index was 114 , average 14 citations per item worldwide. The total citations and h-index of papers published in China were as follows: 353 total citations, 7.06 citations per item, and $10 \mathrm{~h}$-index. High contribution journals, authors, institutions and the top 10 most cited articles on labor analgesia in the world and China were also listed.

Conclusion: Labor analgesia research has grown markedly during the 1988-2018 period. Although China had made remarkable achievements, there was a gap in the high-quality studies between China and other leading countries.

Keywords: labor analgesia, bibliometric analysis, trend analysis, China

\section{Introduction}

In a woman's life, labor is seen as one of the most painful events. Severe labor pain affects parturients' physiological and psychological status, causes strongly stress and sympathetic nervous system responses. The anxiety and apprehension of labor pain may even develop to postpartum depression. ${ }^{1,2}$ Labor pain management is part of the most important tasks an anesthesiologist needs to deal with, the lack of pain relief during labor is the major reason that women request cesareans. In China, the cesarean rate was estimates of 58\% in 2010, far more than the WHO accept the ideal cesarean rate at $10 \%$ to $15 \%$. $^{3}$ Skilled labor pain management can reduce the rate and the complications of cesarean section. With the two-child policy in 
China, the number of parturients has increased dramatically, labor analgesia more should be valued. ${ }^{4}$ Along with these policies and economic growth, Chinese scientific research grows rapidly in labor analgesia field, and various related research results that focus on labor analgesia were published worldwide in recent decades. However, little is known at a broader scale regarding gross tends in labor analgesia research efforts in China and the world.

Bibliometric analysis is a set of statistical methodology based on citation counts and patterns, can be used to evaluate the quality and influence of scientific articles in a research field. By calculating individual or institution's research output, we can better know the improvement and contribution of researchers, organizations in this specific academic field. Moreover, bibliometric analysis revealing historical development, quantifying existing trends, and predicting the future in a given research domain. Using bibliometric analysis to measure and rank research output has been applied to a wide spectrum of specialties in respiratory medicine, cancer, urology, and transplantation..$^{5-9}$

The aim of this study is to quantitatively analyze the research progress and growing trend in labor analgesia during 1988-2018 and make clear the China's contribution to labor analgesia management by utilizing the bibliometrics analysis to evaluate the quantity and quality of researches. Our study also intends to highlight the most prolific areas of research in this field.

\section{Methods}

\section{Ethical Approval}

This study was a bibliometric analysis for published articles which can be downloaded from the public databases, considering that, we did not apply for the ethical approval.

\section{Data Sources}

All data were acquired on July 22, 2019. We searched the Scopus (Elsevier, Netherlands), PubMed, Web of Science (WOS) and the China National Knowledge Infrastructure (CNKI) online database to identify all articles relating to labor pain or labor analgesia published between 1988 and 2018. Research types, including reviews, basic research, clinical trials, case reports were classified according to the PubMed. The Web of Science (WOS) online database was searched for analysis the research categories, average citations per item, h-index, and journal impact factors (IF) from Journal Citation Reports (JCR) (Clarivate Analytics, 2018 from Thomson Reuters).

\section{Search Strategy}

Two independent reviewers (H.Z and B-X.Z.) reviewed the literature for relevant articles to enhance the search sensitivity. The search strategy used in the fields of title, abstract, and keywords. The search terms were: TITLEABS-KEY (labor AND analgesia) OR TITLE-ABS-KEY (labor AND pain AND management)) AND PUBYEAR > 1987. In PubMed, the search terms were (("labour"[All Fields] OR "labor, obstetric"[MeSH Terms] OR ("labor"[All Fields] AND "obstetric"[All Fields]) OR "obstetric labor"[All Fields]) AND ("analgesia"[MeSH Terms] OR "analgesia"[All Fields])) OR (("labor pain"[MeSH Terms] OR ("labor"[All Fields] AND "pain"[All Fields]) OR "labor pain"[All Fields]) AND "management”[All Fields])) AND ("1988/01/01"[PDAT]: “2018/12/31"[PDAT]). Literature type included reviews, basic research, clinical trials and case report. In WOS, the search terms were (labor analgesia) OR (labor pain management) AND year $=(1988-2018)$. In CNKI online database, the search terms were: Theme $=$ (labor analgesia) AND year $=(1988-2018)$. There was no language restriction. Inclusion criteria for identified citations were articles related to labor analgesia research. Exclusion criteria were 1) published before 1988 or after 2018, and 2) publications with insufficient data for screening and analysis. The research progress and growing trend were quantitatively analyzed by total publications, research types, research institutions, journal impact factors, author's contribution, and funding support. Total citations frequency, average citations per item and h-index were used to evaluate literature quantity.

\section{Statistical Analysis}

SPSS 20.0 (Chicago, USA) was used for statistical analyses. Descriptive statistical analyses were mainly used.

\section{Results \\ Labor Analgesia-Related Articles in the World and in China}

Based on search criteria, a total of 8028 articles were identified via Scopus database as labor analgesia research articles published during the targeted period from 1988 to 2018 all over the world. Nearly 120 countries/regions participated in global labor analgesia research. Among them, the USA published the largest number of articles $(2204,27.45 \%)$, pursued by the United Kingdom (1197, 14.91\%), Canada (483, 6.2\%). China had published 175 articles $(2.18 \%)$, ranking the 11 th, 
followed after the USA, the United Kingdom, Canada, Australia, France, Spain, Sweden, Germany, Italy, India (Figure 1A). The global number of publications regarding labor analgesia showed a positive growth trend, from 81 in 1988 to 423 in 2018 (Figure 1B). In China, the former labor analgesia-related article was published in 1992 from the Scopus database. The number of annual publications displayed a remarkably positive growth trend, from 1 in 1992 to 23 in 2018 (Figure 1C), likes global publication tendency.

\section{The Top 10 Most Cited Articles in the Field of Labor Analgesia in the World and China}

The top 10 most cited labor analgesia-related articles including title, author, journal, publication year, journal impact factor, the total number of citations from Scoups and CNKI database are listed in [Tables 1-3]. ${ }^{10-38}$

The number of citations for the global top 10 articles ranged from 327 to 671 . The most cited article (671 times cited) was published in 2004 in Clinical Pharmacokinetics by Grond et al that described the clinical pharmacology of tramadol. ${ }^{10}$ Among these articles, ${ }^{10-19}$ the latest was by Hodnett et al published in 2011 and cited for 340 times. ${ }^{17}$ While the article by Wang et al described a randomized controlled trial used epidural analgesia in the latent phase of labor and the risk of cesarean delivery, ${ }^{20}$ published in 2009 in Anesthesiology is the most cited article (79 times cited) from Chinese researchers. Among the top 10 most frequently cited articles on labor analgesia in the world, three papers ${ }^{14,17,19}$ in Cochrane Database of Systematic Reviews ( $\mathrm{IF}=7.755)$, two papers each were published in Anesthesiology ${ }^{11,16} \quad(\mathrm{IF}=6.424)$, American Journal of Obstetrics and Gynecology ${ }^{12,15}(\mathrm{IF}=6.12)$, one each in Clinical Pharmacokinetics ${ }^{10} \quad(\mathrm{IF}=4.68)$, Journal of Maternal-fetal and Neonatal Medicine ${ }^{13} \quad(\mathrm{IF}=1.569)$, Psychosomatic Medicine ${ }^{18}$ (IF=3.937). In Chinese journals, according to CNKI database, the most cited article (270 times cited) was published in 2000 in Chinese Journal of Practical Gynecology and Obstetrics by Shao et al, ${ }^{29}$ which was the clinical study on analgesic labor with inhaling Nitrous Oxide.
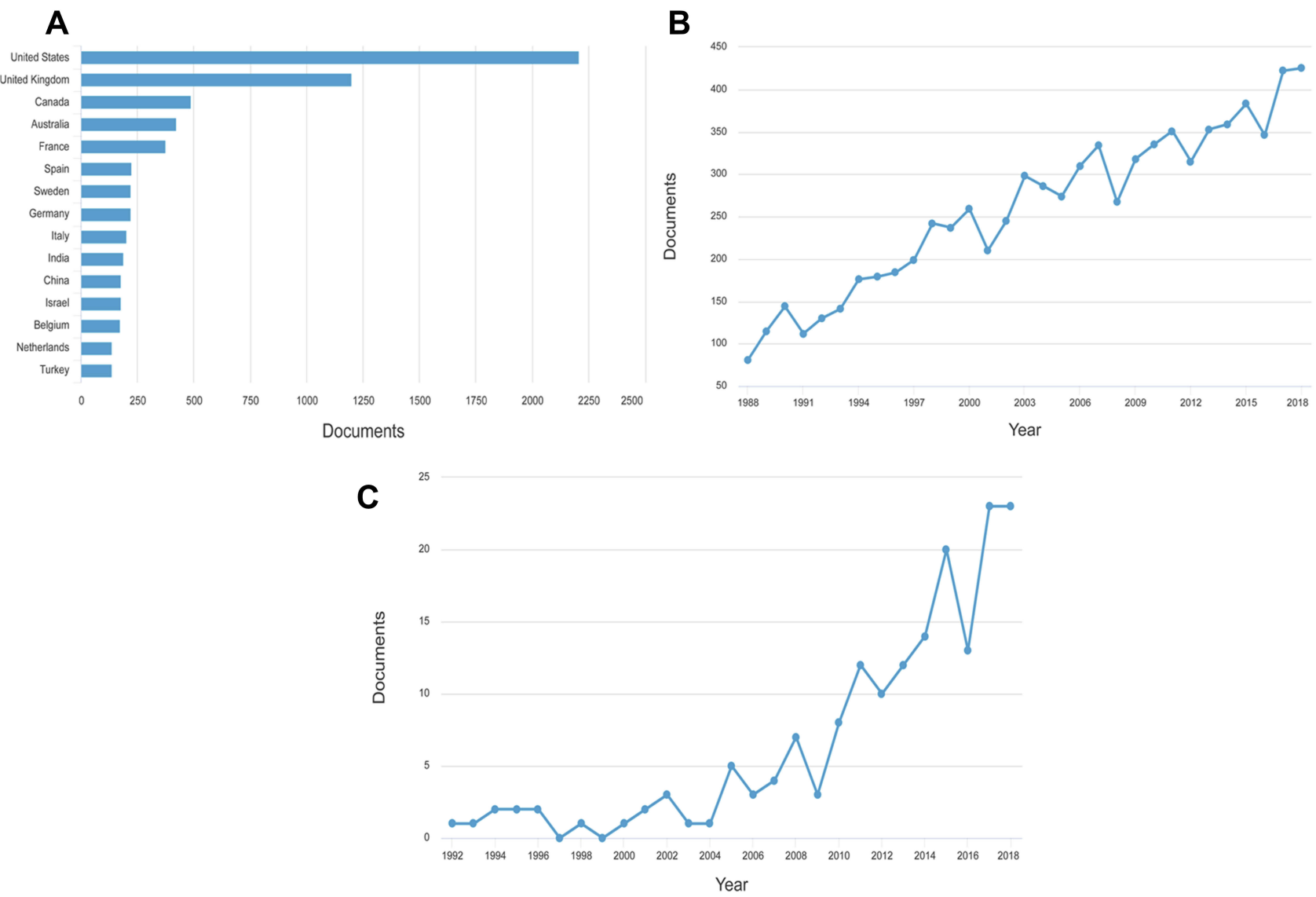

Figure I Labor analgesia-related articles in the world and in China. (A) The number of labor analgesia-related publications from the top I5 Countries/Regions. (B) The global number of publications each year. (C) The number of publications in each year from China. 
Table I The Top 10 Most Frequently Cited Articles on Labor Analgesia in the World

\begin{tabular}{|c|c|c|c|c|c|}
\hline Title & Author & Journal & Year & IF & $\begin{array}{l}\text { Times } \\
\text { Cited }\end{array}$ \\
\hline Clinical pharmacology of tramadol ${ }^{10}$ & Grond, S, et al & $\begin{array}{l}\text { Clinical } \\
\text { Pharmacokinetics }\end{array}$ & 2004 & 4.68 & 671 \\
\hline $\begin{array}{l}\text { Severe neurological complications after central neuraxial blockades in } \\
\text { Sweden } 1990-1999^{11}\end{array}$ & Moen, $\mathrm{V}$, et al & Anesthesiology & 2004 & 6.424 & 614 \\
\hline $\begin{array}{l}\text { Pain and women's satisfaction with the experience of childbirth: } \\
\text { A systematic review }{ }^{12}\end{array}$ & Hodnett, E & $\begin{array}{l}\text { American Journal of } \\
\text { Obstetrics and } \\
\text { Gynecology }\end{array}$ & 2002 & 6.12 & 491 \\
\hline $\begin{array}{l}\text { Depression and anxiety during pregnancy: A risk factor for obstetric, fetal } \\
\text { and neonatal outcome? A critical review of the literature }{ }^{13}\end{array}$ & Alder, J, et al & $\begin{array}{l}\text { Journal of Maternal- } \\
\text { Fetal and Neonatal } \\
\text { Medicine }\end{array}$ & 2007 & 1.569 & 418 \\
\hline Continuous support for women during childbirth ${ }^{14}$ & Hodnett, E, et al & $\begin{array}{l}\text { Cochrane Database of } \\
\text { Systematic Reviews }\end{array}$ & 2007 & 7.755 & 410 \\
\hline $\begin{array}{l}\text { The effect of intrapartum epidural analgesia on nulliparous labor: } \\
\text { a randomized, controlled, prospective trial }{ }^{15}\end{array}$ & Thorp, JA, et al & $\begin{array}{l}\text { American Journal of } \\
\text { Obstetrics and } \\
\text { Gynecology }\end{array}$ & 1993 & 6.12 & 363 \\
\hline $\begin{array}{l}\text { Practice guidelines for obstetric anesthesia: An updated report by the } \\
\text { American Society of Anesthesiologists Task Force on obstetric } \\
\text { anesthesia }^{16}\end{array}$ & Hawkins, J.L, et al & Anesthesiology & 2007 & 6.424 & 362 \\
\hline Continuous support for women during childbirth ${ }^{17}$ & Hodnett, E, et al & $\begin{array}{l}\text { Cochrane Database of } \\
\text { Systematic Reviews }\end{array}$ & 2011 & 7.755 & 340 \\
\hline $\begin{array}{l}\text { Antepartum depressive symptomatology is associated with adverse } \\
\text { obstetric and neonatal outcomes }{ }^{18}\end{array}$ & $\begin{array}{l}\text { Chung, T.K.H, } \\
\text { et al }\end{array}$ & $\begin{array}{l}\text { Psychosomatic } \\
\text { Medicine }\end{array}$ & 2001 & 3.937 & 334 \\
\hline Epidural versus non-epidural or no analgesia in labour ${ }^{19}$ & $\begin{array}{l}\text { Anim-Somuah, } \\
\text { M, et al }\end{array}$ & $\begin{array}{l}\text { Cochrane Database of } \\
\text { Systematic Reviews }\end{array}$ & 2005 & 7.755 & 327 \\
\hline
\end{tabular}

\section{Diffrent Article Types and Research} Categories in the World and China

From the PubMed database, the total of 7349 publications was distributed into different document types. In the past 30 years, clinical trials with 1403 papers, accounting for $19.09 \%$ of the total labor analgesia papers. Additionally, $1211 \mathrm{RCTs}$ (16.48\%), 1160 reviews $(15.78 \%)$ and 722 case reports $(9.82 \%)$ were published in this field all over the world. From the Scopus database, $68.2 \%$ papers of all documents were articles (Figure 2A). In the subject area of labor analgesia research field, medicine takes $83.1 \%$ and nursing takes $6.9 \%$ (Figure 2B). According to the WOS database, there were 221 research categories on labor analgesia articles all over the world; these research categories may have to overlap with each other. Among which Obstetrics Gynecology (6065, 72.314\%), Reproductive Biology (5751, 68.57\%), Anesthesiology (5687, 67.807\%), Pharmacology Pharmacy
(3436, 40.97\%), and Neurosciences Neurology (3025, $36.07 \%$ ) were the most common areas (Figure 2C). The research categories of Chinese articles on labor analgesia are similar to the global articles (Figure 2D).

\section{Citations and h-Index Analysis in the World and China}

According to the WOS database, 8387 publications were included in the analysis. The total citations were 76,207, average 9.086 citations per item, and the h-index was 114 , average 14 citations per item during the past 30 years worldwide. The USA possessed most frequently citations and h-index, which were higher than that of any other country or region (Figure 3). The USA published 2393 papers, with 37,610 total citations and an average 15.72 citations per item, the h-index was 89 . There was a huge gap between China and other developed countries. The 
Table 2 The Top 10 Most Frequently Cited Articles on Labor Analgesia in China

\begin{tabular}{|c|c|c|c|c|c|}
\hline Title & Author & Journal & Year & IF & $\begin{array}{l}\text { Times } \\
\text { Cited }\end{array}$ \\
\hline $\begin{array}{l}\text { Epidural analgesia in the latent phase of labor and the risk of cesarean } \\
\text { delivery: A five-year randomized controlled trial }{ }^{20}\end{array}$ & Wang, $F$, et al & Anesthesiology & 2009 & 6.424 & 79 \\
\hline $\begin{array}{l}\text { Evidence-based obstetrics in four hospitals in China: An } \\
\text { observational study to explore clinical practice, women's preferences } \\
\text { and provider's views }{ }^{21}\end{array}$ & Qian, X, et al & $\begin{array}{l}\text { BMCc Pregnancy and } \\
\text { Childbirth }\end{array}$ & 2001 & 2.413 & 50 \\
\hline Electro-acupuncture in relieving labor pain ${ }^{22}$ & Qu, Fan, et al & $\begin{array}{l}\text { Evidence-Based } \\
\text { Complementary and } \\
\text { Alternative Medicine }\end{array}$ & 2007 & 1.984 & 49 \\
\hline $\begin{array}{l}\text { Epidural labor analgesia is associated with a decreased risk of } \\
\text { postpartum depression: A prospective cohort study }{ }^{23}\end{array}$ & Ding, Ting, et al & Anesthesia and Analgesia & 2014 & 3.489 & 34 \\
\hline $\begin{array}{l}\text { Xenon and sevoflurane provide analgesia during labor and fetal brain } \\
\text { protection in a perinatal rat model of hypoxia-ischemia }{ }^{24}\end{array}$ & Yang, Ting, et al & PLoS One & 2012 & 2.776 & 32 \\
\hline $\begin{array}{l}\text { A comparison of remifentanil parturient-controlled intravenous } \\
\text { analgesia with epidural analgesia: A meta-analysis of randomized } \\
\text { controlled trials }{ }^{25}\end{array}$ & Liu, Z.-Q, et al & Anesthesia and Analgesia & 2014 & 3.489 & 28 \\
\hline $\begin{array}{l}\text { Publication trends in acupuncture research: A } 20 \text {-year bibliometric } \\
\text { analysis based on PubMed }\end{array}$ & $\mathrm{Ma}, \mathrm{Y}$, et al & PLoS One & 2016 & 2.776 & 27 \\
\hline $\begin{array}{l}\text { Patient controlled intravenous analgesia with tramadol for labor pain } \\
\text { relief }^{26}\end{array}$ & Long, J, et al & Chinese Medical Journal & 2003 & 1.555 & 27 \\
\hline $\begin{array}{l}\text { Remifentanil for labour analgesia: A double-blinded, randomised } \\
\text { controlled trial of maternal and neonatal effects of patient-controlled } \\
\text { analgesia versus continuous infusion }{ }^{27}\end{array}$ & Shen, M.K, et al & Anaesthesia & 2013 & 5.879 & 26 \\
\hline $\begin{array}{l}\text { Epidural infusions for labor analgesia: } A \text { comparison of } 0.2 \% \\
\text { ropivacaine, } 0.1 \% \text { ropivacaine, and } 0.1 \% \text { ropivacaine with fentany }\left.\right|^{28}\end{array}$ & Lee, B.B, et al & $\begin{array}{l}\text { Regional Anesthesia and } \\
\text { Pain Medicine }\end{array}$ & 2002 & 5.113 & 26 \\
\hline
\end{tabular}

total citations and h-index of papers published in China were 353 total citations, 7.06 citations per item, and 10 h-index.

\section{High Contribution Journals, Authors and Institutions in Labor Analgesia Field in the World and China}

From the Scopus database, in labor analgesia research field, as the official journal of the Obstetric Anaesthetists' Association (OAA), International Journal of Obstetric Anesthesia ranked first the most contribution journal in the world with the largest number of publications with 468 papers in the past 30 years. Followed was Anesthesia and Analgesia with 315 publications, Anaesthesia with 215 publications, Anesthesiology with 185 publications and British Journal of Anaesthesia with 158 publications. The publication trend in the top 5 high contribution journals in labor analgesia field was presented in Figure 4A.

The top 10 high contribution authors are listed in Figure 4B. Kuczkowski, K. M. from the USA published 95 labor analgesia-related documents, followed by Benhamou, D. with 54 documents, Wong, C.A. with 49 documents. Chinese author Shen, Xiaofeng and Wang, Fuzhou from Hospital of Nanjing Medical University published five documents were the high contribution authors among other Chinese authors.

Brigham and Women's Hospital had published labor analgesia related 151 papers, was the highest contribution institution in the world. The top 10 high contribution authors are shown in Figure 4C. Among these institutions, 4 were from the USA (Brigham and Women's Hospital, Harvard Medical School, University of California, San Diego and Stanford University School of Medicine), 2 
Table 3 The Top 10 Most Frequently Cited Articles on Labor Analgesia in Chinese Journals

\begin{tabular}{|c|c|c|c|c|c|}
\hline Title & Author & Journal & Year & IF & $\begin{array}{l}\text { Times } \\
\text { Cited }\end{array}$ \\
\hline Clinical study on analgesic labor with inhaling Nitrous Oxide ${ }^{29}$ & Shao $\mathrm{H}$, et al & $\begin{array}{l}\text { Chinese Journal of Practical } \\
\text { Gynecology and Obstetrics }\end{array}$ & 2000 & - & 270 \\
\hline Labor analgesia: review ${ }^{30}$ & Guo, J. R. et al & $\begin{array}{l}\text { Chinese Journal of Practical } \\
\text { Gynecology and Obstetrics }\end{array}$ & 2004 & - & 162 \\
\hline The importance of labor analgesia in improving perinatal quality ${ }^{31}$ & Yao, T. Y. & $\begin{array}{l}\text { Chinese Journal of Practical } \\
\text { Gynecology and Obstetrics }\end{array}$ & 2000 & - & 150 \\
\hline Feasibility of labour analgesia on a large scale ${ }^{32}$ & $\mathrm{Qu}, \mathrm{Y}$, et al & $\begin{array}{l}\text { Chinese Journal of } \\
\text { Anesthesiology }\end{array}$ & 2003 & - & 145 \\
\hline $\begin{array}{l}\text { Feasibility of combined spinal-epidural anesthesia and patient } \\
\text { controlled epidural analgesia for labor pain relief }{ }^{33}\end{array}$ & $\mathrm{Qu}, \mathrm{Y}$, et al & $\begin{array}{l}\text { Chinese Journal Of } \\
\text { Anesthesiology }\end{array}$ & 2000 & - & $|4|$ \\
\hline Psychotherapy and labor analgesia ${ }^{34}$ & Liu, H.T. & $\begin{array}{l}\text { Chinese Journal of Practical } \\
\text { Gynecology and Obstetrics }\end{array}$ & 2000 & - & 133 \\
\hline Historical status and prospects of labor analgesia ${ }^{35}$ & Jin, J.Y. & $\begin{array}{l}\text { Chinese Journal of Practical } \\
\text { Gynecology and Obstetrics }\end{array}$ & 2000 & - & 130 \\
\hline Clinical study of sufentanil for labor analgesia ${ }^{36}$ & Liu, J.Y. et al & $\begin{array}{l}\text { Chinese Journal of Obstetrics } \\
\text { And Gynecology }\end{array}$ & 2004 & - & 114 \\
\hline Current status and clinical application of labor analgesia ${ }^{37}$ & Xu, M.J, et al & $\begin{array}{l}\text { Chinese Journal of Practical } \\
\text { Gynecology and Obstetrics }\end{array}$ & 2006 & - & 111 \\
\hline Patient-controlled analgesia for labor analgesia ${ }^{38}$ & She, S.Z. & $\begin{array}{l}\text { Chinese Journal of Practical } \\
\text { Gynecology and Obstetrics }\end{array}$ & 2000 & - & 105 \\
\hline
\end{tabular}

were from the UK (Guy's and St Thomas' NHS Foundation Trust, UCL), the University of Toronto and The University of British Columbia was from Canada, Karolinska institution was from Sweden and KK Women's And Children's Hospital was in Singapore. In China, among the institutions participated in research in labor analgesia field. Peking University published 13 articles, produced the most papers in the past three decades. The top 3 affiliations are Peking University published 16 documents, Fudan University with 14 documents, Nanjing Medical University with 10 documents (Figure 4D). There is a huge gap between Chinese institutions and the world's top institutions in labor analgesia research field.

\section{Discussion}

This study analyzed the labor analgesia by applying the bibliometric methods to scientific publications, suggested the changing situation of labor analgesia and the China's achievement and gap over three decades, which helped us to comprehend the global scientific trend and the direction of the scientific and technological innovation in China in labor analgesia research area.

For most women, labor pain is moderate to severe, intensity of the pain is similar to amputation of a finger. In the early stage of labor, pain caused by uterine contractions and cervical dilatation, transmitted through visceral afferent nerves entering the spinal cord from T10 through L1 segments. In later stage, perineal stretching caused painful stimuli, transmits through the pudendal nerve and sacral nerves S2 through S4 segments. ${ }^{39,40}$ Even though labor pain is not life-threatening in healthy parturient women, it can have neuropsychological consequences like postnatal depression and post-traumatic stress disorder, which seriously impact the quality of maternal life. Parturient received analgesia during labor and delivery had lower risks of neuropsychological disorders. The American Society of Anesthesiologists (ASA) and the American College of Obstetricians and Gynecologists highlighted the significance of labor analgesia. ${ }^{41-43}$ The gold standard for labor analgesia is neuraxial blockade which includes a spinal, epidural, or 


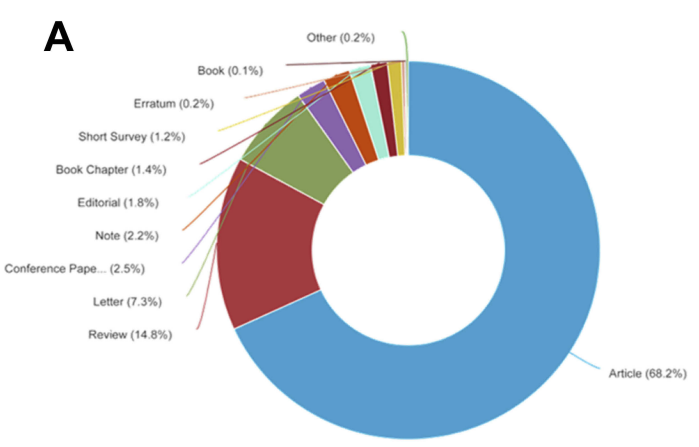

C

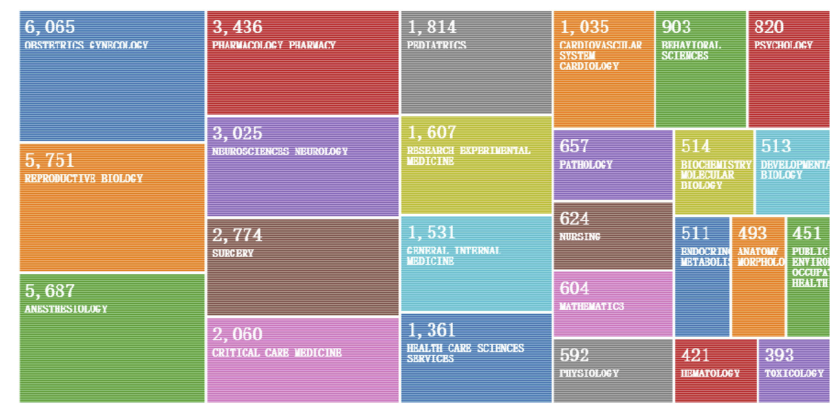

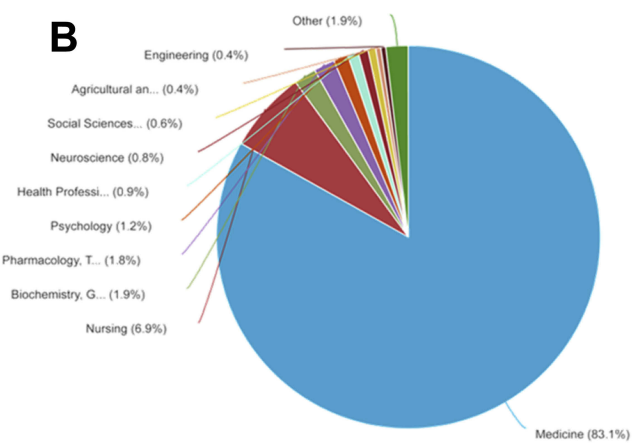

D

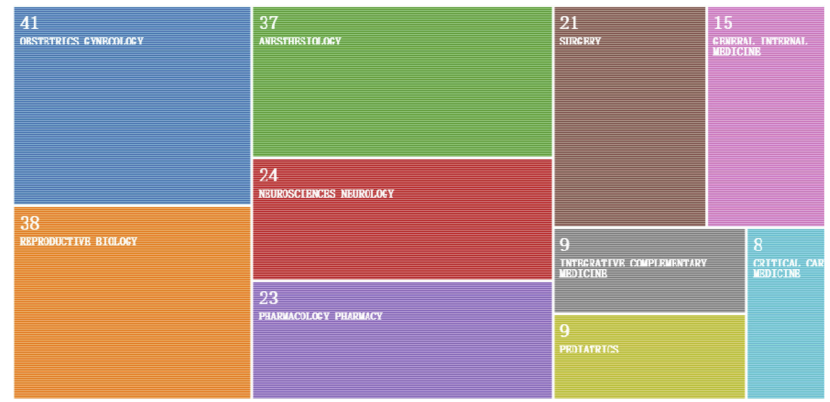

Figure 2 The difference of article types and research categories in the world and China. (A) The types of publications analysis regarding labor analgesia in the past three decades worldwide. (B) The publications distributed in subject area worldwide. Figure $\mathrm{c}$ and $\mathrm{d}$ was plot by using the visualization tools in the web of science, different color area represent the percentage of each research categories, organized by size order. (C) The research categories on labor analgesia in the world. (D) The research categories on labor analgesia in China.

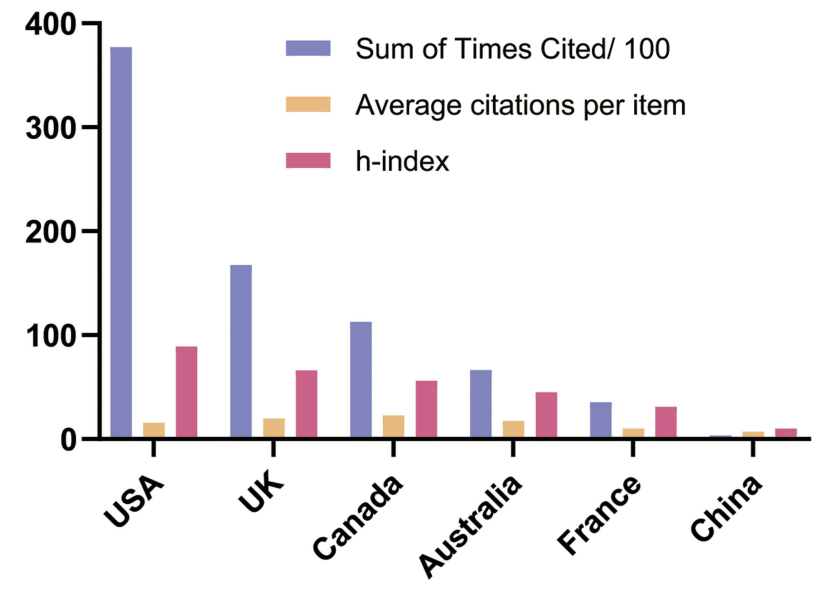

Figure 3 Citations and h-index analysis in the world and China. The total citations, average citations per paper and h-index for labor analgesia articles from top 5 countries and China.

a combined spinal-epidural technique. Pharmacotherapy includes opioids, nonopioids and nitrous oxide. Alternative treatments include yoga, massage, acupuncture, exercise and relaxation techniques during pregnancy. ${ }^{44,45}$

Our bibliometric study of labor analgesia publications from 1988 to 2018 indicates advances in labor analgesia over the last 30 years has resulted in a large and growing literature in China and worldwide. The USA with largest publications, citations and highest h-index held the first place in labor analgesia research area. China had published lots of highly cited articles in Chinese journals in the early years; however, these publications could not be spread to researchers in other countries. In the future, Chinese researchers need to share the results in international journals. Our findings are similar to the bibliometric analysis of neuropathic pain, which analyzed the global trend of neuropathic pain research from 1998 to 2017 and compared China's quantity and quality of neuropathic painrelated publications with other developed countries. The results of the present study also showed, the publication had made a rapid growth after 2015, the year Chinese government implements the two-child policy in China.

We searched Scopus, PubMed, Web of Science and CNKI database in our study. These bibliographic databases cover the most indexed journals in the field of labor analgesia, we searched different databases to do the analysis, hope to reflect the revealing historical development, quantifying existing trends, and predicting the future in labor analgesia research domain. Scopus includes more source titles, we searched it for analysis labor analgesiarelated articles in the world and in China. The Web of Science is recognized for its high-quality inclusion criteria 
A

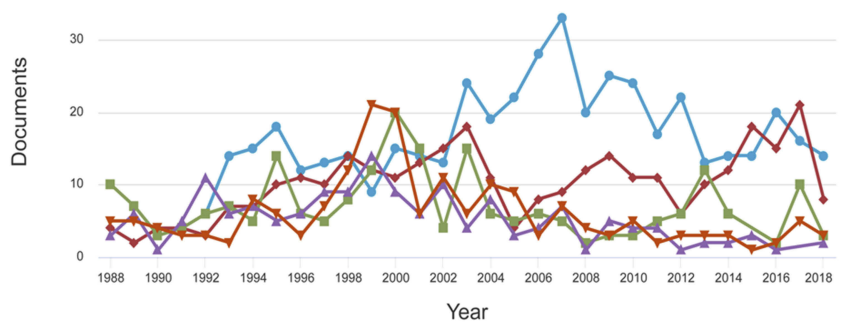

Year

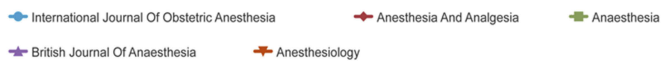

C

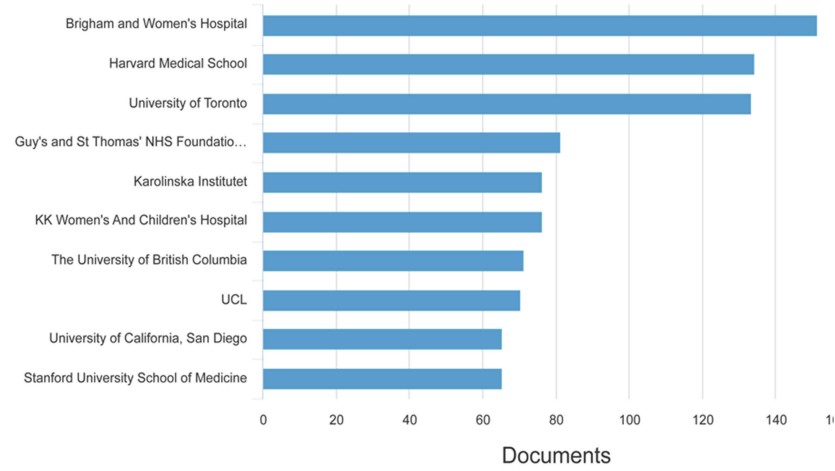

B

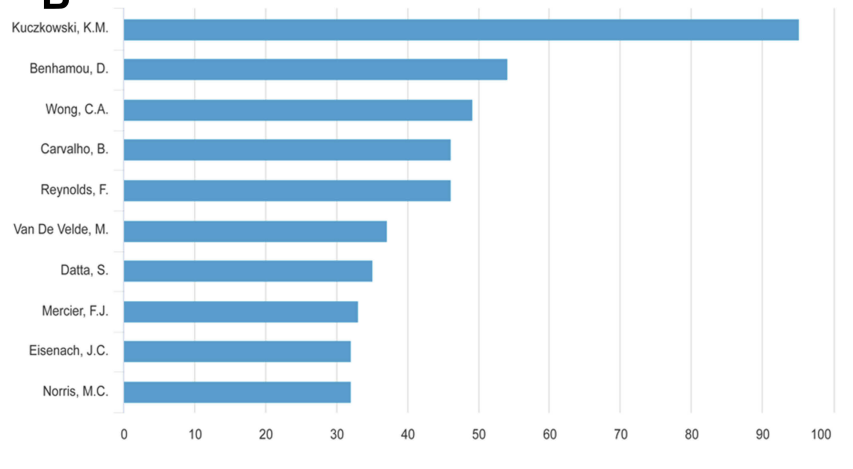

D

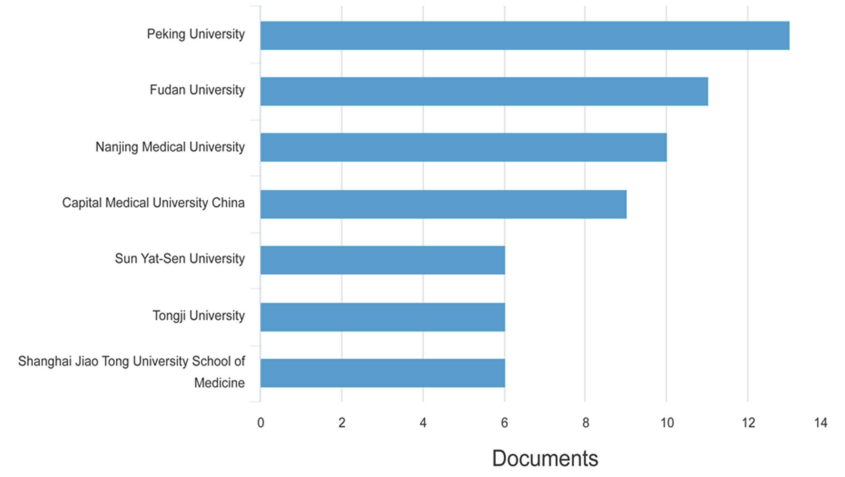

Figure 4 High contribution journals, authors and institutions in labor analgesia field in the world and China. (A) The publication trend in the top 5 high contribution journals in labor analgesia field. (B) The top 10 high contribution authors worldwide. (C) The top 10 high contribution institutions worldwide. (D) The top 5 high contribution institutions in China.

for journals, we searched WOS to evaluate the research categories and the journal impact factors. PubMed was developed and is managed by the National Center for Biotechnology Information (NCBI), comprises over 24 million citations for biomedical literature. In this study, PubMed was used to identify research types. CNKI provides a comprehensive index of the most publications in China, we used it to evaluate Chinese journals.

Compared with the leading countries, the quality of China's papers still needs to be strengthened. There exists a considerable gap in the total citation frequency, average citations per item and h-index. In China, we have a massive amount of clinical resource, the huge population base is a precious resource for clinical trial. Build on these strengths, a more well-designed, high-quality clinical trial could be published in high impact factor journals in the future. With the economic growth of China, the government increased investment in scientific research, create a good environment for researchers. To our knowledge, this is the first quantitatively analyzes the publication tendencies by total publications, research types, research institutions, journal impact factors, author's contribution, total citations frequency, average citations per item and h-index in labor analgesia.

There are some limitations unavoidable in this study. Firstly, even though we searched Scopus, Web of Science, PubMed and CNKI database, the number of medical journals from various countries is still limited. Other databases are also available for bibliometric studies, such as CINAHL and Embase. We used the PubMed database; however, without the filters to identify the basic research, it is difficult to systematically classify publications as basic vs. clinical. Secondly, even though two dependent reviewers (H.Z and B-X.Z.) did the search process, the results were according to the inclusion and exclusion criteria and search filters. Due to the lack of manually review each publication, there might be confounding bias. Thirdly, due to some research outcomes may involve in international collaboration with different countries or institutions, the contributions of authors or institutions were not equal in a given article. At this point, the results of the contribution of authors and institutions could cause bias in the study. 


\section{Conclusion}

In conclusion, this study performed a bibliometric analysis of publications in the field of labor analgesia. In the past 30 years, labor analgesia research had made impressive growth. Both the increase in the publication quantity as well as the impact factor of journals. Although China had made great achievements, there was a gap in the highquality studies between China and other leading countries.

\section{Author Contributions}

All authors contributed to conception and design, acquisition of data, analysis and interpretation of data. All authors drafted and revised the manuscript, approved the final version to be published and agree to be accountable for the contents and integrity of this manuscript.

\section{Disclosure}

The authors have no conflicts of interest to declare.

\section{References}

1. Lang AJ, Sorrell JT, Rodgers CS, Lebeck MM. Anxiety sensitivity as a predictor of labor pain. Eur J Pain. 2006;10(3):263-270. doi:10.1016/j.ejpain.2005.05.001

2. Riazanova OV, Alexandrovich YS, Ioscovich AM. The relationship between labor pain management, cortisol level and risk of postpartum depression development: a prospective nonrandomized observational monocentric trial. Rom $J$ Anaesth Intensive Care. 2018;25 (2):123-130. doi:10.21454/rjaic.7518.252.rzn

3. Wang E. Requests for cesarean deliveries: the politics of labor pain and pain relief in Shanghai, China. Soc Sci Med. 2017;173:1-8. doi:10.1016/j.socscimed.2016.11.032

4. Zeng Y, Hesketh T. The effects of China's universal two-child policy. Lancet. 2016;388(10054):1930-1938. doi:10.1016/S0140-6736(16) 31405-2

5. Kolkailah AA, Fugar S, Vondee N, et al. Bibliometric analysis of the top 100 most cited articles in the first 50 years of heart transplantation. $A m$ J Cardiol. 2019;123(1):175-186. doi:10.1016/j.amjcard.2018.09.010

6. Ma Y, Dong M, Zhou K, Mita C, Liu J, Wayne PM. Publication trends in acupuncture research: a 20-year bibliometric analysis based on PubMed. PLoS One. 2016;11(12):e0168123. doi:10.1371/journal. pone. 0168123

7. Rezaee ME, Johnson HA, Munarriz RM, Gross MS. Bibliometric analysis of erectile dysfunction publications in urology and sexual medicine journals. J Sex Med. 2018;15(10):1426-1433. doi:10.1016/ j.jsxm.2018.08.004

8. Ye J, Ding H, Ren J, Xia Z. The publication trend of neuropathic pain in the world and China: a 20 -years bibliometric analysis. $J$ Headache Pain. 2018;19(1):110. doi:10.1186/s10194-018-0941-4

9. Zhu H, Yang X, Qin Q, et al. Report of China's innovation increase and research growth in radiation oncology. Chin $J$ Cancer Res. 2014;26(3):293-298. doi:10.3978/j.issn.1000-9604.2014.06.02

10. Grond S, Sablotzki A. Clinical pharmacology of tramadol. Clin Pharmacokinet. 2004;43(13):879-923. doi:10.2165/00003088-20044 3130-00004

11. Moen V, Dahlgren N, Irestedt L. Severe neurological complications after central neuraxial blockades in Sweden 1990-1999. Anesthesiology. 2004;101(4):950-959. doi:10.1097/00000542-200410000-00021
12. Hodnett ED. Pain and women's satisfaction with the experience of childbirth: a systematic review. Am J Obstet Gynecol. 2002;186(5 SUPPL.):S160-S172. doi:10.1067/mob.2002.121141

13. Alder J, Fink N, Bitzer J, Hösli I, Holzgreve W. Depression and anxiety during pregnancy: a risk factor for obstetric, fetal and neonatal outcome? A critical review of the literature. J Matern Fetal Neonatal Med. 2007;20(3):189-209. doi:10.1080/14767050701209560

14. Hodnett E, Gates S, Hofmeyr GJ, Sakala C. Continuous support for women during childbirth. Cochrane Database Syst Rev. 2007;3. doi:10.1002/14651858.CD003766.pub2

15. Thorp JA, Hu DH, Albin RM, et al. The effect of intrapartum epidural analgesia on nulliparous labor: a randomized, controlled, prospective trial. Am J Obstet Gynecol. 1993;169(4):851-858. doi:10.1016/0002-9378(93)90015-B

16. Hawkins JL, Arens JF, Bucklin BA, et al. Practice guidelines for obstetric anesthesia: an updated report by the American Society of Anesthesiologists Task Force on obstetric anesthesia. Anesthesiology. 2007;106(4):843-863. doi:10.1097/01.anes.0000264744.63275.10

17. Hodnett ED, Gates S, Hofmeyr GJ, Sakala C, Weston J. Continuous support for women during childbirth. Cochrane Database Syst Rev. $2011 ; 2$.

18. Chung TKH, Lau TK, Yip ASK, Chiu HFK, Lee DTS. Antepartum depressive symptomatology is associated with adverse obstetric and neonatal outcomes. Psychosom Med. 2001;63(5):830-834. doi:10.10 97/00006842-200109000-00017

19. Anim-Somuah M, Smyth R, Howell C. Epidural versus non-epidural or no analgesia in labour. Cochrane Database Syst Rev. 2005;4: CD000331.

20. Wang F, Shen X, Guo X, Peng Y, Gu X; Labor Analgesia Examining G. Epidural analgesia in the latent phase of labor and the risk of cesarean delivery: a five-year randomized controlled trial. Anesthesiology. 2009;111(4):871-880. doi:10.1097/ALN.0b013e3181b55e65

21. Qian X, Smith H, Zhou L, Liang J, Garner P. Evidence-based obstetrics in four hospitals in China: an observational study to explore clinical practice, women's preferences and provider's views. BMC Pregnancy Childbirth. 2001;1(1):1. doi:10.1186/1471-2393-1-1

22. Qu F, Zhou J. Electro-acupuncture in relieving labor pain. Evid Based Complement Alternat Med. 2007;4(1):125-130. doi:10.1093/ecam/ ne1053

23. Ding T, Wang DX, Qu Y, Chen Q, Zhu SN. Epidural labor analgesia is associated with a decreased risk of postpartum depression: a prospective cohort study. Anesth Analg. 2014;119(2):383-392. doi:10.1213/ANE.0000000000000107

24. Yang T, Zhuang L, Rei Fidalgo AM, et al. Xenon and sevoflurane provide analgesia during labor and fetal brain protection in a perinatal rat model of hypoxia-ischemia. PLoS One. 2012;7(5):e37020. doi:10. 1371/journal.pone. 0037020

25. Liu ZQ, Chen XB, Li HB, Qiu MT, Duan T. A comparison of remifentanil parturient-controlled intravenous analgesia with epidural analgesia: a meta-analysis of randomized controlled trials. Anesth Analg. 2014;118(3):598-603. doi:10.1213/ANE.0000000000000077

26. Long J, Yue Y. Patient controlled intravenous analgesia with tramadol for labor pain relief. Chin Med J (Engl). 2003;116(11):1752-1755.

27. Shen MK, Wu ZF, Zhu AB, et al. Remifentanil for labour analgesia: a double-blinded, randomised controlled trial of maternal and neonatal effects of patient-controlled analgesia versus continuous infusion. Anaesthesia. 2013;68(3):236-244. doi:10.1111/anae.12098

28. Lee BB, Ngan Kee WD, Lau WM, Wong AS. Epidural infusions for labor analgesia: a comparison of $0.2 \%$ ropivacaine, $0.1 \%$ ropivacaine, and $0.1 \%$ ropivacaine with fentanyl. Reg Anesth Pain Med. 2002;27 (1):31-36. doi:10.1053/rapm.2002.27836

29. Shao H, Lu X, Cheng W, Zhang B, Zheng H. Clinical study on analgesic labor with inhaling nitrous oxide. Chin J Pract Gynecol Obstet. 2000;02:19-21.

30. Guo JR, Jiang H, Cui JJ. Labor analgesia: review. Chin J Pract Gynecol Obstet. 2004;01:64-66. 
31. Yao TY. The importance of labor analgesia in improving perinatal quality. Chin J Pract Gynecol Obstet. 2000;02:3-4.

32. Qu Y, Wu XM, Zhao GL, et al. Feasibility of labour analgesia on a large scale. Chin J Anesth. 2003;04:30-33.

33. Qu Y, Wu XM, Xu CD, Guan TT, Liu LP, Ma Q. Feasibility of combined spinal-epidural anesthesia and patient controlled epidural analgesia for labor pain relief. Chin J Anesth. 2000;04:23-26.

34. Liu HT. Psychotherapy and labor analgesia. Chin J Pract Gynecol Obstet. 2000;02:13-14.

35. Jin JY. Historical status and prospects of labor analgesia. Chin J Pract Gynecol Obstet. 2000;02:5.

36. Liu JY, Li RS, Wu WL, et al. Clinical study of sufentanil for labor analgesia. Chin J Obstet Gynecol. 2004;10:56-57.

37. Xu MJ, Wu XM. Current status and clinical application of labor analgesia. Chin J Pract Gynecol Obstet. 2006;07:548-550.

38. She SZ. Patient-controlled analgesia for labor analgesia. Chin J Pract Gynecol Obstet. 2000;02:7-9.
39. Lowe NK. The nature of labor pain. Am J Obstet Gynecol. 2002;186 (5 Suppl Nature):S16-S24. doi:10.1067/mob.2002.121427

40. Shnol H, Paul N, Belfer I. Labor pain mechanisms. Int Anesthesiol Clin. 2014;52(3):1-17. doi:10.1097/AIA.0000000000000019

41. ACOG committee opinion \#295: pain relief during labor. $J$ Obstet Gynecol. 2004;104(1):213. doi:10.1097/00006250-200407000-00061

42. Heesen M, Klimek M. Obstetric analgesia - update 2016. J Perinat Med. 2017;45(3):281-289. doi:10.1515/jpm-2016-0118

43. Vallejo MC, Zakowski MI, Scavone BM. SOAP delivers: options for labor pain. Anesth Analg. 2016;122(4):1223. doi:10.1213/ANE.0000 000000001138

44. Koyyalamudi V, Sidhu G, Cornett EM, et al. New labor pain treatment options. Curr Pain Headache Rep. 2016;20(2):11. doi:10.1007/ s11916-016-0543-2

45. Likis FE, Andrews JC, Collins MR, et al. Nitrous oxide for the management of labor pain: a systematic review. Anesth Analg. 2014;118(1):153-167. doi:10.1213/ANE.0b013e3182a7f73c

\section{Publish your work in this journal}

The Journal of Pain Research is an international, peer reviewed, open access, online journal that welcomes laboratory and clinical findings in the fields of pain research and the prevention and management of pain. Original research, reviews, symposium reports, hypothesis formation and commentaries are all considered for publication. The manuscript management system is completely online and includes a very quick and fair peer-review system, which is all easy to use. Visit http:// www.dovepress.com/testimonials.php to read real quotes from published authors. 